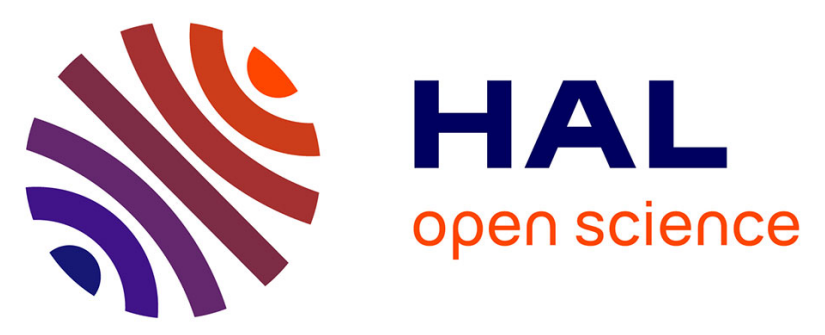

\title{
Climatic controls of a keystone understory species, Sasamorpha borealis, and an impact assessment of climate change in Japan
}

\author{
Tsuyama, Nakao, Matsui, Higa, Horikawa, Kominami, Tanaka
}

\section{To cite this version:}

Tsuyama, Nakao, Matsui, Higa, Horikawa, et al.. Climatic controls of a keystone understory species, Sasamorpha borealis, and an impact assessment of climate change in Japan. Annals of Forest Science, 2011, 68 (4), pp.689-699. 10.1007/s13595-011-0086-y . hal-00930818

\section{HAL Id: hal-00930818 https://hal.science/hal-00930818}

Submitted on 1 Jan 2011

HAL is a multi-disciplinary open access archive for the deposit and dissemination of scientific research documents, whether they are published or not. The documents may come from teaching and research institutions in France or abroad, or from public or private research centers.
L'archive ouverte pluridisciplinaire HAL, est destinée au dépôt et à la diffusion de documents scientifiques de niveau recherche, publiés ou non, émanant des établissements d'enseignement et de recherche français ou étrangers, des laboratoires publics ou privés. 


\title{
Climatic controls of a keystone understory species, Sasamorpha borealis, and an impact assessment of climate change in Japan
}

\author{
Ikutaro Tsuyama • Katsuhiro Nakao • Tetsuya Matsui • \\ Motoki Higa • Masahiro Horikawa • Yuji Kominami • \\ Nobuyuki Tanaka
}

Received: 19 March 2010 /Accepted: 22 November 2010/Published online: 27 May 2011

(C) INRA and Springer Science+Business Media B.V. 2011

\begin{abstract}
- Introduction The aims of this study were to identify the climatic conditions controlling the distribution of Sasamorpha borealis and to assess the impact of climate change on the species in Japan.

- Materials and methods The relationship between $S$. borealis distribution and climatic variables in the Japanese Archipelago was explored using classification tree analysis.
\end{abstract}

\section{Handling Editor: Gilbert Aussenac}

Electronic supplementary material The online version of this article (doi:10.1007/s13595-011-0086-y) contains supplementary material, which is available to authorized users.

I. Tsuyama $(\bowtie) \cdot K$. Nakao $\cdot$ M. Higa $\cdot$ N. Tanaka

Department of Plant Ecology,

Forestry and Forest Products Research Institute,

Matsunosato 1,

Tsukuba, Ibaraki, Japan 3058687

e-mail: Aquarianleo@gmail.com

\section{T. Matsui}

Hokkaido Research Station,

Forestry and Forest Products Research Institute,

7 Hitsujigaoka, Toyohira-ku,

Sapporo, Hokkaido, Japan 0628516

\section{Horikawa}

Toyota Biotechnology and Afforestation Laboratory,

Toyota Motor Corporation,

1099 Aza Marune, Oaza Kurozasa, Miyosi-cho,

Nishikamo-gun, Aichi, Japan 4700201

\section{Y. Kominami}

Kansai Research Center,

Forestry and Forest Products Research Institute,

68 Nagaikyutaro, Momoyama-cho,

Fushimi-ku, Kyoto, Japan 6120855
Potential habitat maps under the current and future climates were generated at about 1-km spatial resolution.

- Results The model was highly accurate. Although snow cover has been thought to be the most important factor controlling $S$. borealis distribution, we revealed that the species requires high precipitation during the growing season even in humid Japanese environments. Areas with high summer (May-September) precipitation (PRS) were classified as potential habitat irrespective of other climatic conditions. In areas with moderate PRS, potential habitat was limited to cooler and less snow-covered areas and areas with low PRS were classified as non-habitat. The high fitness of the predicted to the observed distributions suggested that $S$. borealis could have survived throughout the Japanese Archipelago during the glacial period.

- Conclusion In future climates, 29.0-39.1\% of the current potential habitat was predicted to change to non-habitat due to increasing dryness in the growing season. Areas with high precipitation remained a potential habitat for $S$. borealis.

Keywords Dwarf bamboo - Species distribution model . Snow cover Summer precipitation $\cdot$ Empty habitat

\section{Introduction}

Understanding species-environment relationships has always been a central issue in ecology and biogeography, and the dominant role of climate in the distribution of organisms has been recognized (e.g., Woodward 1996). Effective natural ecosystems conservation and management requires that the climatic controls of current plant distributions be identified and used to predict future plant distributions 
under a warmer climate (Hannah et al. 2002). The potential magnitudes of future changes to plant distributions will be important guides for efficient conservation policy development (e.g., choosing optimum species/sites for monitoring and preservation).

Globally averaged land-surface air and sea-surface temperatures rose by $0.74^{\circ} \mathrm{C}$ over the past hundred years (between 1906 and 2005) and are projected to rise 1.8$4.0^{\circ} \mathrm{C}$ by $2090-2099$ (IPCC 2007). Global warming is predicted to cause substantial changes in the structure and function of terrestrial ecosystems (Hannah et al. 2002). Several ecological phenomena including range shifts toward the poles and advancement of spring events around the world are hypothesized to have been caused by climate change (Parmesan and Yohe 2003).

Species distribution models (SDMs) have been widely used to identify the environmental factors that determine species' distributions and predict potential habitat for the species. SDMs have recently been recognized as an important tool for assessing the impact of environmental change. In Europe and the USA, numerous SDM studies have characterized a species' habitat based on empirical relationships between observed species distributions and environmental variables (i.e., niche-based modeling approaches; e.g., Pearson and Dawson 2003; Thuiller et al. 2005). In addition, some SDM studies have used other new approaches that characterize a species' habitat based on the response of the species to environmental conditions (i.e., process-based modeling approaches; e.g., Morin and Thuiller 2009). In East Asia, however, few studies have applied SDM models using niche-based modeling approaches, to say nothing of process-based modeling approaches.

A keystone species is defined as biomass dominant within a functional group (Begon et al. 1996). Because keystone species have a disproportionate impact on ecosystem function (Begon et al. 1996), these species should be preferentially studied. Changes in keystone species habitat or biomass could have substantial impacts on natural ecosystems.

Dwarf bamboos (Poaceae: Bambusoideae) are evergreen clonal shrubby plant species. They occur in East and Southeast Asia and in South America. In montane and subalpine zones, dwarf bamboos dominate the understory and interfere with the growth of other plant species (Nakashizuka 1987).

In Japan, dwarf bamboo species prevalence corresponds to differences in snow accumulation on the western (Sea of Japan side) and eastern sides (Pacific Ocean side) of Japan (Suzuki 1978). Dwarf bamboo sections Macrochlamys and Sasa of genus Sasa (Suzuki 1978) are adapted to a snowy climate and occur on the Sea of Japan side. In contrast, dwarf bamboo taxa adapted to a less snowy climate such as genus Sasamorpha and section Crassinodi of genus Sasa (Suzuki 1978) occur on the Pacific Ocean side. This difference in dwarf bamboo species between the Sea of Japan side and the Pacific Ocean side is one of the most striking characteristics of Japanese forest vegetation.

In our previous studies, the potential habitats of two snow-adapted dwarf bamboo taxa were predicted to decrease by $53.1-67.9 \%$ due to future decreases in snow cover and increases in temperature (Tsuyama et al. 2008a, b). The target species of the present study was Sasamorpha borealis (Hack.) Nakai, which occurs mainly in Japan and to a limited extent on the Korean Peninsula. The northern and southern limits of its global distribution are Hokkaido and southern Kyushu, respectively, in Japan. S. borealis often dominates the forest floor in the cool-temperate zone on the Pacific Ocean side of Japan (Fig. 1). Climatic conditions controlling the $S$. borealis distribution have not been clarified at a national scale (i.e., interregional scale). After Suzuki (1961) showed that the species occurs in areas with a maximum snow depth of $<75 \mathrm{~cm}$ in northern Honshu, snow cover was believed to be the most
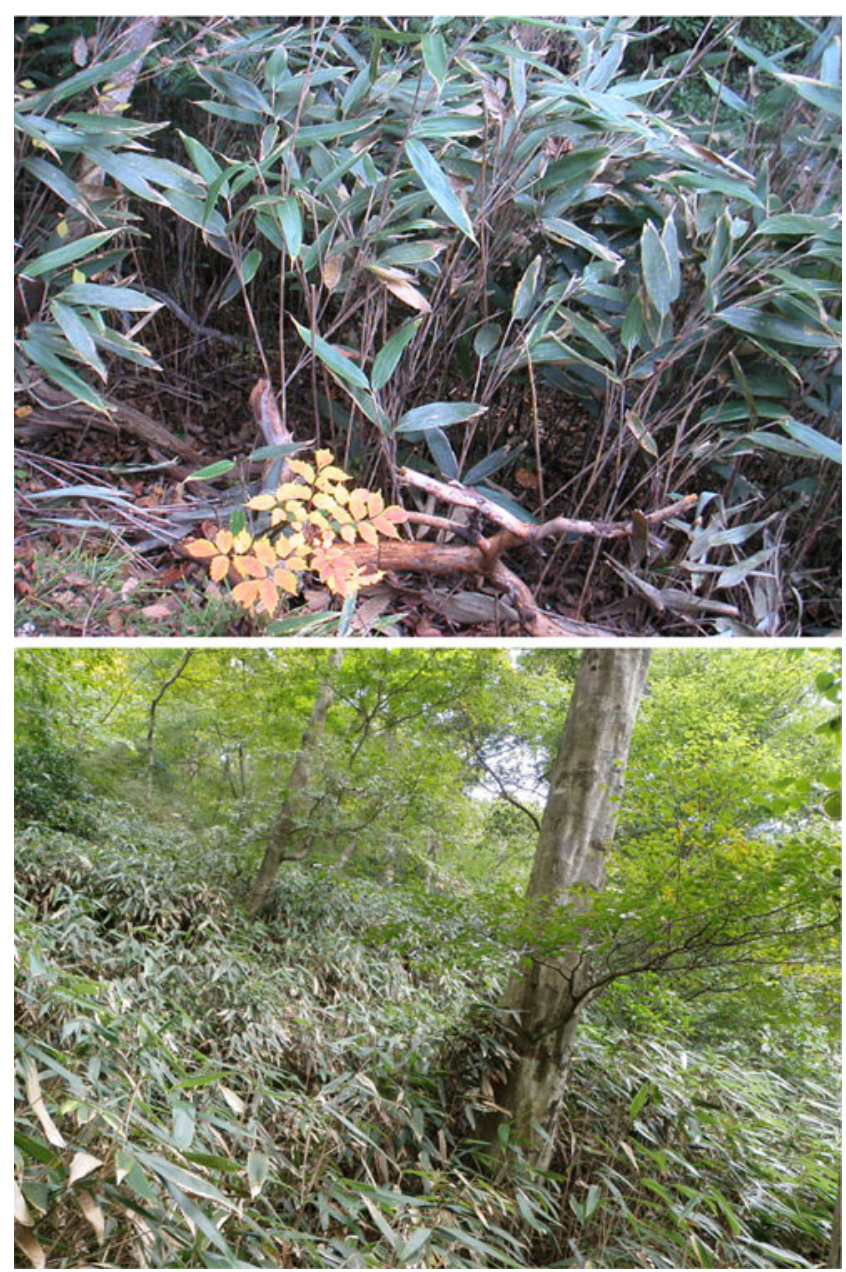

Fig. 1 Upper, S. borealis; lower, a cool-temperate deciduous forest with the understory dominated by $S$. borealis 
important factor controlling its distribution. Estimated reductions in snow cover caused by climate change would facilitate the expansion of $S$. borealis into currently snowy areas in Japan. Meanwhile, the lower and southern range limits of the species would be expected to shift upward or northward due to expected competition with warm-temperate plants.

Previous studies have indicated that $S$. borealis influences not only the regeneration of other plants (Yuruki et al. 1977), but also animal fitness. For example, the sika deer depends on $S$. borealis for food, especially in winter (Saruki et al. 2004). S. borealis also influences the population density and diversity of birds, which use its dense shrub cover for shelter (Hino 2006). These reports suggest that $S$. borealis is a keystone species of Japanese cool-temperate forests. Furthermore, S. borealis provides ecosystem services such as erosion and landslide control (Yuruki et al. 1977). Therefore, determining what controls the distribution of $S$. borealis and projecting the changes of habitat suitability under climate change are important for forest ecosystems conservation and management.

Morin and Thuiller (2009) argued that the combined use of both niche- and process-based modeling approaches, which are built on different principles, is crucial to obtaining more robust and accurate results when assessing the impact of climate change on plant distributions. Niche-based models characterize a species' habitat based on realized niche, which may not represent the physiological limits on a species' distribution (Pearson and Dawson 2003). One of the main advantages of niche-based models is their relative simplicity, which allows them to be applied easily to a large number of species. The main criticisms of these models are that validation is difficult and the predictions have a high uncertainty (Morin and Thuiller 2009). On the other hand, process-based models aim to identify the fundamental niche that represents the limits on a species' distribution, but is not realized. Process-based models enable processes involved in range shifts or extinction to be highlighted, but their calibration requires a large amount of ecophysiological knowledge and data, and intraspecies variation makes defining precise limits to a species' climatic tolerance difficult (Pearson and Dawson 2003).

In this study, as the ecophysiological data available for the target species were limited, we only used a niche-based modeling approach. However, we extracted ecological meaning from the SDM and discussed the results in relation to the known ecological traits of $S$. borealis.

The objectives of this study were to determine:

1. The climatic conditions controlling the distribution of S. borealis

2. The vulnerable and sustainable potential habitats of $S$. borealis under different climate change scenarios

\section{Materials and methods}

\subsection{Study area and distribution data for S. borealis}

The study area included all of Japan except areas that were not modeled in the future climate change scenarios (Fig. S1). The spatial resolution was $30^{\prime \prime} \mathrm{N} \times 45^{\prime \prime} \mathrm{E}$ (ca. $1 \times 1 \mathrm{~km}$ ), referred to as Third Mesh cells in Japan. In total, 361,379 cells were used in this analysis.

Distribution data for $S$. borealis were extracted from the Phytosociological Relevé Database (PRDB; Tanaka 2007) and digitized Suzuki's distribution data (SDD; Suzuki 1978). PRDB is a database composed of plot (relevé) data collected throughout Japan using the phytosociological method. The relevé data were digitized into $\mathrm{PRDB}$ from a variety of sources including published and unpublished literature, as well as original data collected in the field (Tanaka 2007).

A relevé datum includes community structure and species names and their dominance in each layer of a plot. As of 2008, PRDB had 22,653 relevés digitized. These relevé data were obtained from 1948 to 1999 with $95 \%$ of the relevés obtained between 1968 and 1987. Data were recorded in third mesh cells when their location could be determined within ten connecting cells or a $5 \mathrm{~km}$ radius.

We extracted 15,809 presence/absence distribution data points for $S$. borealis from PRDB. To prevent repetition, only one record was included per third mesh cell $($ ca. $1 \times 1 \mathrm{~km}) \times$ $100 \mathrm{~m}$ in elevation. When more than one presence record was obtained for the spatial unit, only one presence was recorded regardless of the existence of an absence record. When no presence record was obtained for a spatial unit, but an absence occurred, then an absence was recorded. After this thinning of the data, 702 presence and 8,430 absence records were obtained (Fig. 2). Hereafter, these presence/ absence data are referred to as the "training data."

To validate the accuracy of the model, the predicted distribution of $S$. borealis was compared to SDD. SDD based on a dot map represent the distribution of all Japanese Bambusoideae at a spatial resolution of about $10 \times 10 \mathrm{~km}$ (Suzuki 1978). Presence dots in the map were converted into a dataset structured by second mesh cells, each measuring $5^{\prime}$ in latitude and $7^{\prime} 30^{\prime \prime}$ in longitude (ca. $10 \times 10 \mathrm{~km}$ ). The number of presence second mesh cells for S. borealis was 185 (Fig. S2).

\subsection{Current climatic data}

In addition to climatic factors, plant distribution is also controlled by factors such as soil type and topography (Woodward 1996). Because the aim of this study was to identify the climatic controls and assess the impact of climate change on $S$. borealis at a national scale, only climatic factors were used to develop the species distribu- 
Fig. 2 Horizontal and vertical distributions of $S$. borealis based on the training data. Solid and open circles show the presence and absence, respectively, of $S$. borealis

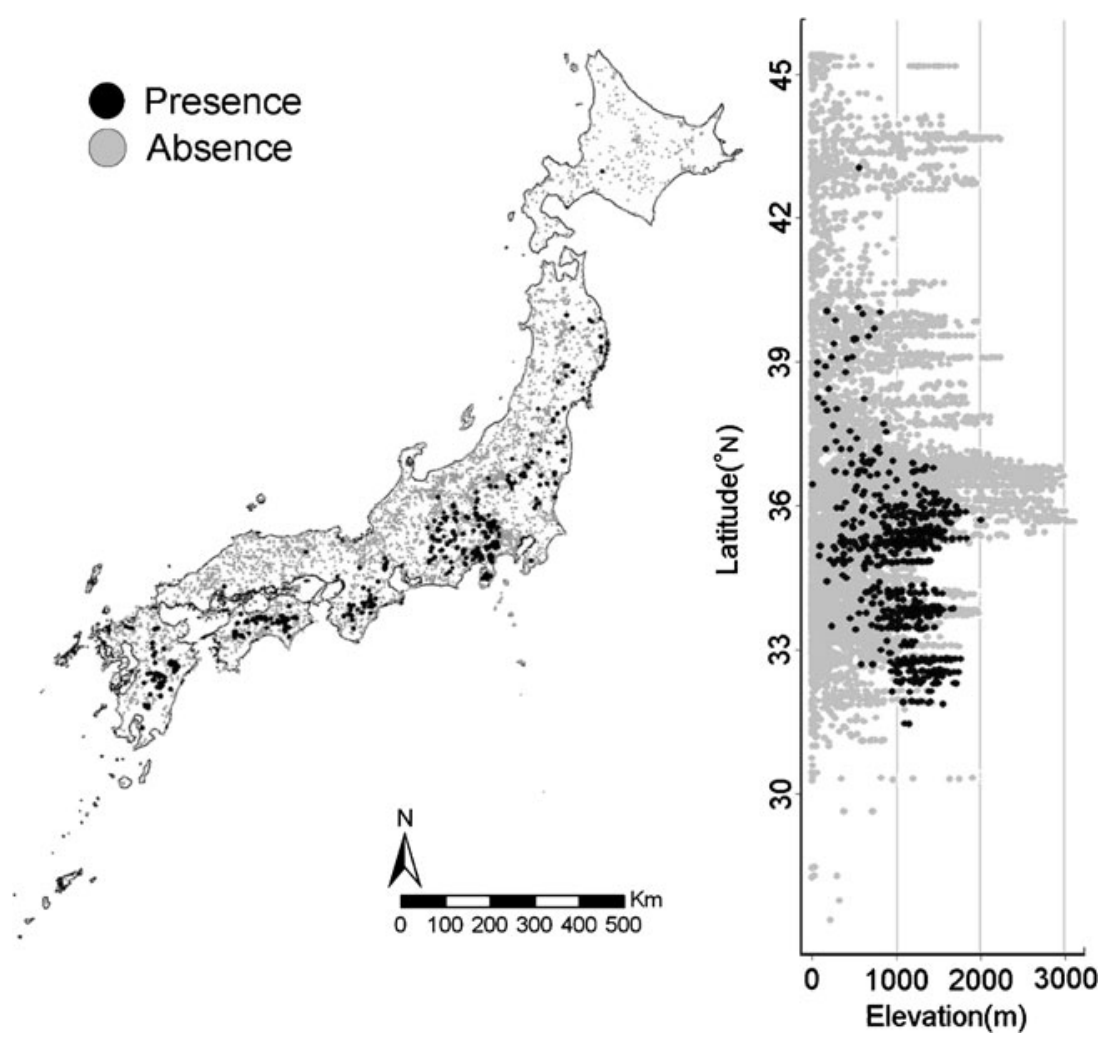

tion model. Although anthropogenic effects such as urbanization and cultivation may also be influential, land use variables were omitted because $S$. borealis mainly grows in mountainous regions with relatively little human influence.

Third mesh climatic data from the Japan Meteorological Agency (1996) were used to model the current distribution of $S$. borealis. The dataset is based on meteorological temperature observations collected between 1953 and 1982 and precipitation data collected between 1953 and 1976. The climatic data for each relevé were extracted from the mesh climatic data by matching the third mesh code. Monthly mean temperature for each relevé was adjusted based on the elevational difference between relevés and the third mesh cells by using monthly lapse rates.

The following five climatic factors used in the models are important for plant growth and survival. The warmth index (WI), defined as the annual sum of positive differences between the monthly mean temperature and $+5^{\circ} \mathrm{C}$ (Kira 1991), is a measure of effective heat quantity requisite for plant growth. WI is one of the most useful variables for explaining the vegetation patterns of East Asia (Kira 1991). The monthly mean of daily minimum temperature of the coldest month (TMC) is a measure of extreme cold, which controls the altitudinal or northern range limit of evergreen broad-leaved forests (Ohsawa 1993). Summer (May-September) precipitation (PRS) is a measure of growing season water supply. Maximum snow water equivalent (MSW) is a measure of snow accumulation, and winter (November-April) rainfall (WR) is a measure of winter water supply.

MSW and WR were calculated by aggregating daily changes of snowfall, rainfall, and meltwater (degree-day method), based on the daily climatic dataset supplied from the Automated Meteorological Data Acquisition System and the mesh climatic data (see Kominami et al. 2005).

\subsection{Climate change scenarios}

For the impact assessment of climate change, we applied a Regional Climate Model with a spatial resolution of $20 \times 20 \mathrm{~km}$ (hereafter, RCM20; Japan Meteorological Agency 2004) and the Model for Interdisciplinary Research on Climate (hereafter, MIROC; K-1 Model Developers 2004). The RCM20 scenario was generated using a Regional Spectral Model exclusively for Japan based on the A2 scenarios from the Special Report on Emissions Scenarios (SRES), which assume increasing population, low economic growth, and technological change (Japan Meteorological Agency 2004). The RCM20 scenario for 2081-2100 was spatially interpolated into the Second Mesh cells using the inverse-distanceweighted interpolation method (Yokozawa et al. 2003). It was then further interpolated spatially into the third mesh cells (Tsuyama et al. 2008a).

The MIROC scenario was generated using the Atmosphere-Ocean Coupled General Circulation Model based 
on SRES scenario A1B, which assumes rapid economic growth, quick spread of new and efficient technologies, and a balanced emphasis on all energy sources (K-1 Model Developers 2004). This scenario for 20812100 was spatially interpolated from about $1.125^{\circ}$ to the third mesh cells using the inverse distance-weighted interpolation method (Yokozawa et al. 2003).

The five climatic variables in each third mesh cell were calculated using the RCM20 and MIROC scenarios in the same manner as the current climate. Comparing the current climate to the RCM20 and MIROC scenarios within the study area, the average annual temperature increased from $10.5^{\circ} \mathrm{C}$ to $13.3^{\circ} \mathrm{C}$ and $14.8^{\circ} \mathrm{C}$, respectively, and the following changes (current climate to the RCM20 and MIROC scenarios) were observed in each climatic variable: WI 86.9 to 110.9 and $127.4, \mathrm{TMC}-6.0^{\circ} \mathrm{C}$ to -3.0 and $-1.4^{\circ} \mathrm{C}$, PRS 1,038 to 1,220 and $1,304 \mathrm{~mm}$; MSW 159.0 to 82.7 and $9.0 \mathrm{~mm}$; and WR 491 to 539 and $668 \mathrm{~mm}$ (Fig. S3).

\subsection{Species distribution model}

A classification tree model (Clark and Pregibon 1992) was used to analyze the importance and threshold of each climatic variable in determining the spatial distribution of $S$. borealis. A classification tree model is a recursive data partitioning algorithm. The dataset is iteratively split into subsets based on the typical value of a predictor variable, which minimizes the deviance of subsets. The partitioning process is repeated until each subset becomes relatively homogeneous. A tree model provides a hierarchical view of the relationships between species and environmental variables and allows finding interactions and hierarchical relations among environmental variables. The model is one of the few methods that can model interactive effects of two or more variables and can represent them in an easily readable fashion.

Presence/absence data of $S$. borealis were used as a response variable and the five climatic variables were used as explanatory variables. The most appropriate tree size in the classification tree model was obtained after cross-validation to avoid over- or under-fitting of the model (Clark and Pregibon 1992). Deviance-weighted scores (DWS), defined as the sum of the reduction of deviance between parent nodes and children nodes (Matsui et al. 2004), were calculated to evaluate the importance of each explanatory variable. S-PLUS6.2 J (Mathsoft Inc.) was used for this analysis.

2.5 Validation of the species distribution model and computation of potential habitat

Model performance was evaluated by two methods. The area under the curve (AUC) of the receiver operating characteristic (ROC; Metz 1978) was calculated based on predicted presence/absence data and the validation data bootstrapped from all of the training data with 100 repetitions. In addition, we calculated model sensitivity based on the predicted presence/absence data and another dataset (SDD). Although these methods have been commonly used for validating SDMs, they tend to overestimate the model fit because spatial autocorrelation inherently exists between the training and validation datasets (Morin and Thuiller 2009).

The ROC curve is obtained by plotting sensitivity (i.e., the true positive rate) versus 1 specificity (i.e., the falsepositive rate) with various probability thresholds. Given the many factors that influence the actual distribution of species, maximizing the fit between predicted suitabilities and the observed distribution is likely to underestimate the extent of potential habitat (Pearson et al. 2004). Therefore, to minimize the false-negative fraction (the proportion of false-negative predictions vs. the number of actual positive sites), we defined a threshold value by assigning a cutoff sensitivity as recommended by Pearson et al. (2004). In this study, we applied the threshold of occurrence probability defined by sensitivity values of $95 \%$. The threshold was defined based on model predictions for the entire training dataset. We defined areas with probabilities greater than or equal to the threshold probability as potential habitat and areas with probabilities smaller than the threshold value as non-habitat.

Potential habitat was divided into suitable and marginal habitat. To define the suitable habitat for $S$. borealis, the optimum probability threshold was identified by specifying the nearest occurrence probability to the ideal point (top-left corner) of the ROC curve. Suitable habitat was defined as areas with occurrence probabilities greater than or equal to the optimal threshold probability and most of these areas coincided with the observed distribution of the species. Marginal habitat, defined as areas with occurrence probabilities lower than the optimal threshold probability (Tsuyama et al. 2008a), included areas where climatic conditions were not so suitable for species growth, and therefore, the chance of occurrence or dominance was relatively low (Tsuyama et al. 2008a).

Based on the classification tree model, potential habitat under the current and future climate was predicted. Empty habitat, areas of potential habitat under current climatic conditions but where the species was not present, was also identified. To evaluate the impact of climate change on the distribution of $S$. borealis, the areas of suitable and marginal habitat under current and future climatic conditions were compared. To evaluate the effect of migration ability of the species, potential habitat was predicted assuming full and no migration ability. 


\section{Results}

\subsection{Distribution pattern of S. borealis}

S. borealis occurs on the Pacific Ocean side of Japan, from Hokkaido to Kyushu, in the training data and SDD (Fig. 2 and Fig. S2). From Tohoku northward, $S$. borealis occurs at low to middle (ca. 1,000 m) elevations, whereas in the Chubu Mountains, it occurs at low to high (ca. 2,000 m) elevations. From the Kii Peninsula westward (hereafter, western Japan), S. borealis occurs at elevations higher than $1,000 \mathrm{~m}$.

The ranges of climatic variables for $99 \%$ of the presence records in the training data were as follows: WI, 42.4-119.1; TMC, -11.4-0.45 ${ }^{\circ}$; PRS, 717.5-2,624.3 mm; MSW, 3.0$347.9 \mathrm{~mm}$; and WR, 180.1-858.2 $\mathrm{mm}$.

3.2 Prediction accuracy and threshold probability for habitat category divisions

The tree diagram for $S$. borealis showed 20 terminal nodes after optimal pruning based on cross-validation (Fig. 3). The mean value and standard deviation of the AUC were $0.91 \pm 0.006$ based on 100 replications of the ROC analysis. The AUC value was categorized as "excellent" according to Swets (1988). The sensitivity of the predicted potential habitat for SDD was 0.85 (158/185 records). Therefore, we judged the model for $S$. borealis to be reasonably accurate.

The two threshold occurrence probabilities, defined by a sensitivity value of $95 \%$ and the ROC analysis, were 0.0068 and 0.123 , respectively. Therefore, we defined the areas with probabilities larger than or equal to 0.0068 as potential habitat; areas with probabilities smaller than 0.0068 were defined as non-habitat. Potential habitat was divided into marginal habitat with $0.0068 \leq$ probability $<$ 0.123 and suitable habitat with a probability of $\geq 0.123$.

3.3 Climatic factors and thresholds controlling S. borealis distribution

PRS and WI accounted for larger DWS (37.4\% and 32.2\% of all DWS, respectively) than other variables (MSW, 18.9\%; WR, 6.0\%; TMC, 5.5\%). Climatic conditions of potential habitat for $S$. borealis differed depending on the magnitude of PRS (Fig. 3). Areas with a PRS greater than $1,522.5 \mathrm{~mm}$ were classified as potential habitat irrespective of other climatic variable conditions (Fig. 3, right branch under the first division of the tree diagram). For areas with PRS less than $1,522.5 \mathrm{~mm}$, potential habitat was limited to the areas in which MSW of $<229.3 \mathrm{~mm}$ and WI of $<98.3$ (nodes C, G, H, J, M, N, and P). Areas with PRS less than $715.5 \mathrm{~mm}$ were classified as non-habitat (node T). Areas with PRS of $<1,522.5$ and MSW of $\geq 229.3 \mathrm{~mm}$ (node S), and areas with PRS of $<1,522.5 \mathrm{~mm}, \mathrm{MSW}$ of $<229.3 \mathrm{~mm}$, and WI of $\geq 98.3$ (node $R$ ) were also classified as nonhabitat. Of the records classified as suitable habitat, $95.7 \%$ (1,962/2,050 records) had the following climatic conditions: PRS of $\geq 715.5 \mathrm{~mm}$, WI of $<87.0-98.3$, and MSW of $<229.3-263.9 \mathrm{~mm}$.

\subsection{Current potential habitat of S. borealis}

The distribution of predicted potential habitat was similar to that based on the training data and SDD. Suitable habitat
Fig. 3 The classification tree model for S. borealis. Start from the top node of the tree. If the data meet the climatic condition of the node, go left, otherwise go right. The number of terminal nodes after pruning was 20 from A to $\mathrm{T}$. The numbers written beneath each node show the occurrence probability and $n$ under the climatic conditions of each node. The terminal nodes enclosed by the solid line indicate suitable habitat and those enclosed by the dashed line show marginal habitat. Other terminal nodes are considered non-habitat. The numbers in parentheses show the number of data points classified into the node

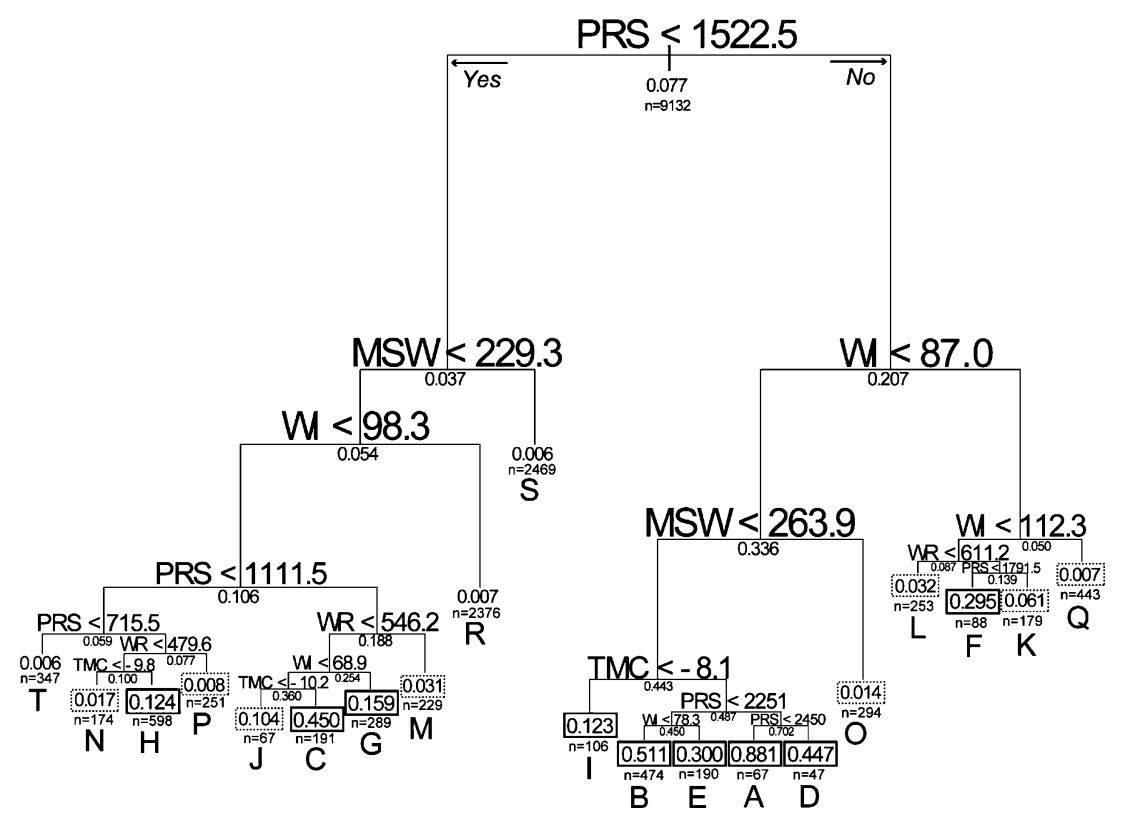


with no observed presences (i.e., empty suitable habitat) was only identified on Yakushima Island (Fig. 2, Fig. S2 and Fig. 4a).

Suitable habitats with high PRS (PRS of $\geq 1,522.5 \mathrm{~mm}$, nodes A, B, D, E, F, and I) were predicted to occur in mountainous areas on the Pacific Ocean side of the Izu Peninsula westward (Figs. 3 and $4 a$ ). In contrast, suitable habitats with low PRS (PRS of $<1,522.5 \mathrm{~mm}$, node $\mathrm{C}, \mathrm{G}, \mathrm{H}$ ) were predicted to occur in coastal areas of southern Hokkaido, at lower elevations on the Pacific Ocean side of Tohoku, at lower elevations in Chubu, the inner Kii Peninsula, and mountainous areas facing the Seto Inland Sea. Marginal habitat occurred in lowlands on the Pacific Ocean side of Hokkaido and western Japan, the lowlands of Chubu, and mountainous areas on the Japan Sea side of Chugoku district.
3.5 Changes in potential habitat under the climate change scenarios

Potential S. borealis habitats under future climates were predicted based on the tree model (Fig. 4b, c). The current potential habitat included 120,781 cells. Assuming full migration, S. borealis potential future habitat included 149,306 and 179,379 cells under the RCM20 and MIROC scenarios, respectively. Assuming no migration, the potential future habitat decreased to 85,724 and 73,601 cells under the RCM20 and MIROC scenarios, respectively (Table 1). The suitable habitat was predicted to decrease irrespective of migration and the marginal habitat was predicted to increase or slightly decrease. Of the current 48,838 cells of suitable habitat, $25.3 \%$ (12,344 cells) and $5.3 \%(2,601$ cells $)$ were predicted to remain, and $49.3 \%$
Fig. 4 Spatial distributions of the predicted potential habitat for $S$. borealis under $a$ the current climate, $b$ the RCM20 scenario for 2081-2100, and $c$ the MIROC scenario for 20812100. "Suitable" in the legend means suitable habitat, "Marginal" refers to marginal habitat, and "Non" indicates non-habitat. The letters in the legend refer to the corresponding terminal node names in the classification tree

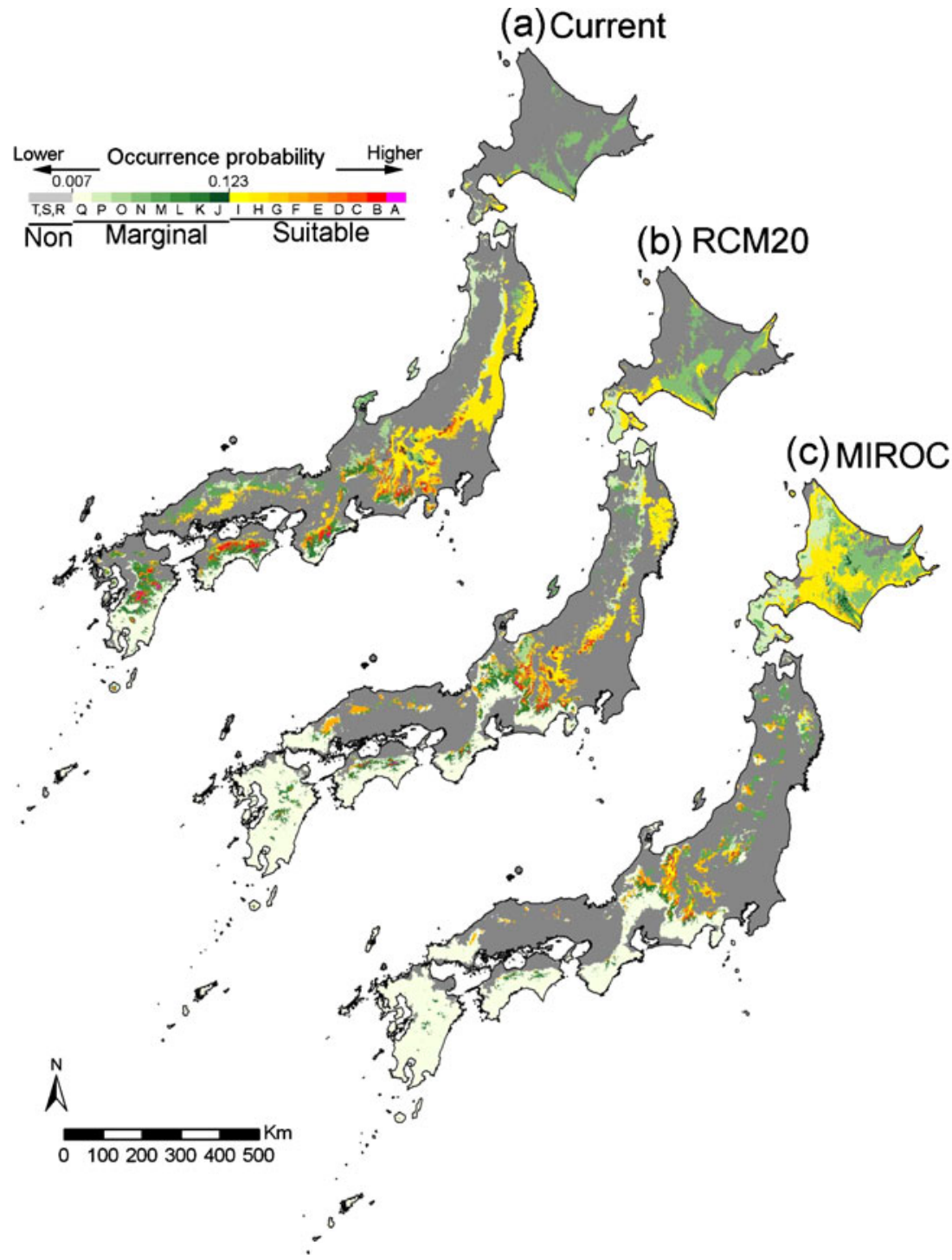


Table 1 The number of third mesh cells of potential habitat, suitable habitat, and marginal habitat for S. borealis under the current climate and the 2081-2100 climates, under conditions of no and full migration

\begin{tabular}{llccr}
\hline Climate scenarios & Migration & Potential habitat & Suitable habitat & Marginal habitat \\
\hline Current & - & $120,781(100)$ & $48,838(100)$ & $71,943(100)$ \\
RCM2O (2081-2100) & No & $85,724(71.0)$ & $20,743(42.5)$ & $64,981(90.3)$ \\
& Full & $149,306(123.6)$ & $34,253(70.1)$ & $115,053(160.0)$ \\
MIROC (2081-2100) & No & $73,601(60.9)$ & $10,403(21.3)$ & $63,198(87.8)$ \\
& Full & $179,379(148.5)$ & $44,497(91.1)$ & $134,882(187.5)$
\end{tabular}

Percentages of each habitat type to the current extent of the habitat type are shown in parentheses

$(24,099)$ and $64.3 \%(31,422)$ were predicted to change to non-habitat under the RCM20 and MIROC scenarios, respectively.

The potential habitat predicted to change to non-habitat under the future climates was located in areas of low PRS, such as the Pacific Ocean side of Tohoku, lower elevations of Chubu, and mountainous areas facing the Seto Inland Sea (Fig. S4). In contrast, the potential habitat predicted to change to suitable habitat occurred in coastal areas of southern Hokkaido, higher elevations on the Pacific Ocean side of Honshu southward, and higher elevations in Chugoku district.

Comparing the latitudinal distribution of suitable habitat under the current climate with those under the RCM20 and MIROC scenarios, suitable habitat shifted poleward throughout Japan (the median rates under the RCM20 scenario: about $35 \mathrm{~km} /{ }^{\circ} \mathrm{C}$, MIROC: about $172 \mathrm{~km} /{ }^{\circ} \mathrm{C}$; Figs. 4 and 5). From
Tohoku southward, the suitable habitat shifted to higher elevations (the median rates under the RCM20 scenario: about $120 \mathrm{~m} /{ }^{\circ} \mathrm{C}, \mathrm{MIROC}$ : about $165 \mathrm{~m} /{ }^{\circ} \mathrm{C}$ ).

\section{Discussion}

We identified the most important climatic variables and the thresholds controlling the distribution of $S$. borealis using the classification tree model, high-resolution (ca. $1 \mathrm{~km}$ ) climatic data, and a nationwide relevé database. Because this species occurs mainly in Japan, with small remote populations also located on the Korean Peninsula, a model based on Japanese distribution data is appropriate for identifying the main habitat conditions. The high accuracy of the model suggested that the distribution of $S$. borealis at a national scale can be explained by climatic variables.
Fig. 5 Vertical distributions of potential habitat for $S$. borealis under $\mathbf{a}$ the current climate, $\mathbf{b}$ the RCM20 scenario for 20812100 , and $\mathbf{c}$ the MIROC scenario for 2081-2100. Black circles indicate suitable habitat, dark gray circles represent marginal habitat, and gray circles refer to non-habitat

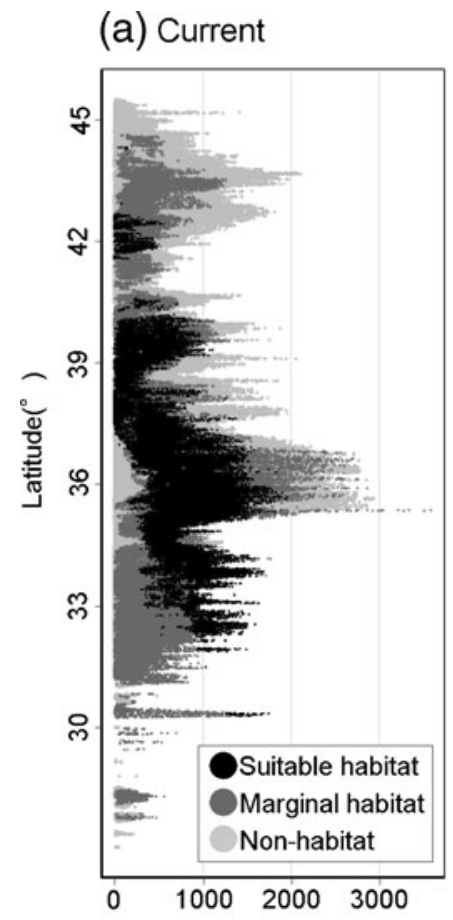

(b) RCM20 (2081-2100)

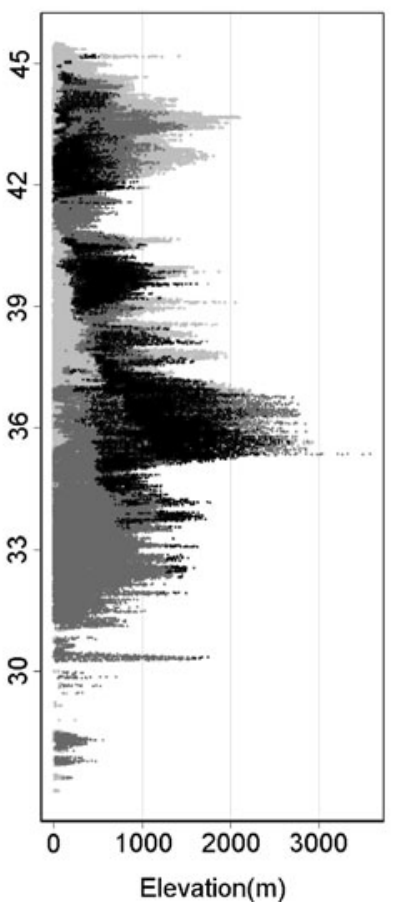

(c) MIROC (2081-2100)

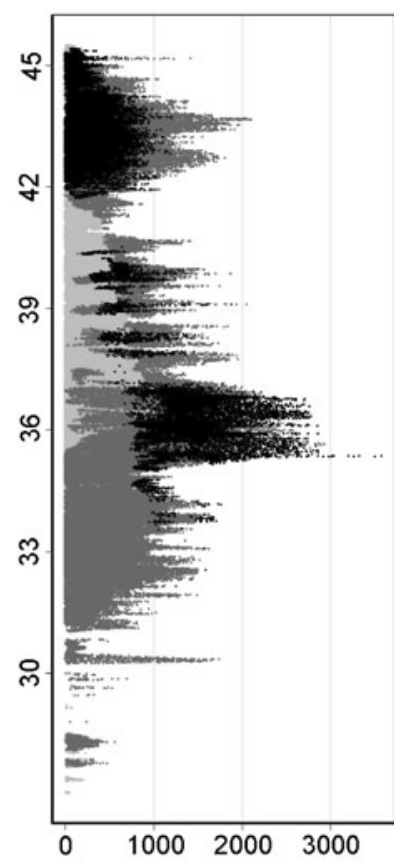


4.1 Climatic conditions controlling the distributions of $S$. borealis

Due to Japan's wet and humid climate, previous studies have assumed that precipitation was not an important factor influencing the distribution of plant species (Ohsawa 1993). Previous studies have also indicated that maximum snow depth (MSD) was the most important factor controlling S. borealis (Suzuki 1961). In contrast, our study revealed that PRS was the most important factor controlling $S$. borealis habitat suitability. MSW contributed to $S$. borealis distributions at more local scales (Fig. 3).

Based on regional studies in northeastern Honshu (ca. 500-600-km scale), Suzuki (1961) proposed that only MSD determined $S$. borealis's range. On a national scale, however, MSD was not sufficient to explain the distribution of $S$. borealis. Climatic conditions controlling the regional distribution of a species cannot necessarily be extrapolated to larger scales or other regions because regional-scale controlling factors vary with environmental conditions at larger scales (Pearson and Dawson 2003). In fact, the theory of Suzuki (1961) was applicable to the conditions of PRS of $<1,522.5 \mathrm{~mm}$ in the classification tree diagram for $S$. borealis (Fig. 3). Assuming that the snow density is between 0.3 and $0.4 \mathrm{~g} \mathrm{~cm}^{-3}$, the second division in the classification tree, MSW of $<229.3 \mathrm{~mm}$, is equivalent to MSD of $<57.3-76.4 \mathrm{~cm}$. This value is in close agreement with the theory of Suzuki (1961) that $S$. borealis occurs in areas with MSD of $<75 \mathrm{~cm}$.

We found that $S$. borealis requires heavy precipitation during the growing season (more than $715.5 \mathrm{~mm}$ ). The ecological traits of $S$. borealis, including large leaf-area, competitiveness, preference for cool or wet habitats, shallow roots, and low mobility (Yuruki et al. 1977), are features common to taxa predisposed to drought impact (Archaux and Wolters 2006). In low PRS areas, this species only occurs on steep slopes (Suzuki 1961). In high PRS areas, however, the species is found on almost all topographies (Yuruki et al. 1977). These facts suggest that $S$. borealis is not drought tolerant. We suggest that this is the reason why PRS is the most important climatic factor affecting the distribution of $S$. borealis under Japan's humid climate.

The tree model showed that a MSW value of $229.3 \mathrm{~mm}$ was the threshold for the distribution of $S$. borealis in areas with PRS of $<1,522.5 \mathrm{~mm}$. Mechanical damage caused by snow pressure (e.g., snow settlement, glide, and creep pressure) and/or short growing season are considered to be direct limiting factors. In addition, a WI of 98.3 was the threshold condition in areas with PRS of $<1,522.5 \mathrm{~mm}$ and MSW of $<229.3 \mathrm{~mm}$. Dryness in the growing season caused by increased WI is expected to be the direct limiting factor.
4.2 Potential habitat and observed distributions of $S$. borealis

The projected potential habitat for S. borealis was in good agreement with the actual distribution of the species based on training data and SDD (Fig. 2, Fig. S2 and Fig. 4). Empty suitable habitat, suitable areas based on current climatic conditions but where the species was not present, was only projected to occur in mountainous areas of Yakushima Island. S. borealis may not have been able to disperse to Yakushima Island because of the island's distance from the main island.

The empty suitable habitat for $S$. borealis was conspicuously smaller than those of snow-adapted dwarf bamboos in sections Sasa and Macrochlamys. Empty suitable habitat for Sasa was projected in mountainous areas of the Kii Peninsula and southern Chubu, and that for Macrochlamys was projected in mountainous areas of Shikoku and central Chubu, in addition to the areas for Sasa (Tsuyama et al. 2008a, b). In view of these results, we hypothesized that $S$. borealis could survive throughout Japan during the cooler and drier glacial period. Summer precipitation during the glacial period is thought to have been higher than the tolerance limit of $S$. borealis. Meanwhile, snow-adapted dwarf bamboos are hypothesized to have been more affected by cold and drought in winter than $S$. borealis because of their high dependence on snow-cover protection (e.g., insulation from cold and drought, and moisture supply).

4.3 Identifying vulnerable and sustainable potential habitats for $S$. borealis

The area of potential habitat was predicted to increase to $123.6-148.5 \%$ of current values under the future climate scenarios of 2081-2100 assuming S. borealis can fully expand to occupy its new potential habitat (namely, full migration; Table 1, Fig. 4). In contrast, the potential habitat was predicted to decrease to $60.9-71.0 \%$ of its current extent assuming $S$. borealis does not migrate from its current potential habitat (namely, no migration). The latter results are considered to be more realistic because of the slow migration speed of the species (usually $1 \mathrm{~m} /$ year).

We identified vulnerable and sustainable habitats for $S$. borealis under the RCM20 and MIROC scenarios. Areas with high PRS (PRS of $\geq 1,522.5 \mathrm{~mm}$ ) were predicted to be less affected by climate change than areas with low PRS (PRS of $<1,522.5 \mathrm{~mm}$ ). Increases in WI are important in areas with low PRS (Fig. 3). Areas in which potential habitat changes to suitable habitat (i.e., sustainable habitat for $S$. borealis) include the middle and high elevations on the Pacific Ocean side of Japan, from Hokkaido to Kyushu (Fig. 4 and Fig. S4). 
Suitable habitat for $S$. borealis was predicted to decrease to $21.3-42.5 \%$ of the current area by $2081-2100$, assuming no migration. Of the current 48,838 cells of suitable habitat, $49.3-64.3 \%$ was predicted to change to non-habitat because of the increase in WI (Table 1, Fig. 4). These areas are vulnerable habitats for $S$. borealis and include the Pacific Ocean side of Tohoku, the lowlands of Chubu, and mountainous areas facing the Seto Inland Sea (Fig. S4). In these vulnerable areas, growth may become difficult due to the water deficit caused by the increase in WI. Plant species that may potentially serve as alternatives to $S$. borealis in terms of ecological function include warmtemperate dwarf bamboos (e.g., section Nezasa). However, complete $S$. borealis replacement is expected to take hundreds or thousands of years because the migration rates of dwarf bamboos are low. Thus, we suspect that $S$. borealis will vanish from these vulnerable habitats before the replacement is completed. Recent increases in the populations of sika deer would aggravate the decline of $S$. borealis because $S$. borealis is intolerant to grazing (Saruki et al. 2004). The structure and biodiversity of forest ecosystems may be irrevocably altered by substantial changes in $S$. borealis biomass due to the synergistic effect of climate change and grazing.

\section{Conclusion}

We developed an accurate SDM predicting the actual distribution of $S$. borealis with little empty habitat. The model identified climatic variables and their threshold values that determine the species' distribution. Although snow cover has been thought to be the most important factor controlling $S$. borealis distribution, the species' habitat is heavily affected by changes in growing season precipitation (PRS), even under the Japanese humid climate. Areas with high PRS (PRS of $\geq 1,522.5 \mathrm{~mm}$ ) were classified as potential habitat irrespective of other climatic conditions. In areas with moderate PRS (715.5 $\leq$ PRS $<1,522.5 \mathrm{~mm}$ ), potential habitat was limited to cooler and less snow-covered areas, and areas with low PRS (PRS of $<715.5 \mathrm{~mm}$ ) were classified as non-habitat. These results were consistent with the ecophysiological traits of S. borealis.

This model is useful for projecting future potential habitats with an uncertainty due to the variation in climate change scenarios. Future species occurrence has another uncertainty because the occurrence will be determined by not only habitat suitability but also ecological processes including migration and extinction of species. Developing models that include ecological processes and monitor vulnerable habitats for species are necessary for forest ecosystem conservation.
Acknowledgments We thank Dr. Erin Conlisk for her useful comments and language help on this manuscript. We also thank the anonymous reviewer and the associate editor Gilbert Aussenac for their valuable comments. This study was funded by a program of the Global Environmental Research of Japan (S-4 and S-8), the Ministry of the Environment.

\section{References}

Archaux F, Wolters V (2006) Impact of summer drought on forest biodiversity: what do we know? Ann For Sci 63:645-652

Begon M, Harper J, Townsend C (1996) Ecology: individuals, populations and communities, 3rd edn. Blackwell Science, Oxford, $1068 \mathrm{p}$

Clark L, Pregibon D (1992) Tree-based models. In: Chambers J, Hastie T (eds) Statistical Models in S. Wadsworth \& Brooks/Cole, California, pp 377-419

Hannah L, Midgley G, Millar D (2002) Climate change-integrated conservation strategies. Glob Ecol Biogeogr 11:485-495

Hino T (2006) The impact of herbivory by deer on forest bird communities in Japan. Acta Zool Sin 52:684-686

IPCC (2007) Climate change 2007: the physical science basis. Contribution of Working Group I to the Fourth Assessment Report of the Intergovernmental Panel on Climate Change. Cambridge University Press, Cambridge, 996 p

Japan Meteorological Agency (1996) Climatic normals for Japan. Japan Meteorological Business Support Center, Tokyo (In Japanese)

Japan Meteorological Agency (2004) MRI-RCM20. Global Environment and Marine Department of Japan Meteorological Agency, Tokyo (In Japanese)

K-1 Model Developers (2004) K-1 coupled GCM (MIROC) description. K-1 Tech Rep 1:1-34

Kira T (1991) Forest ecosystems of east and southeast Asia in a global perspective. Ecol Res 6:185-200

Kominami Y, Tanaka N, Endo Y, Niwano S (2005) Estimation of snow distribution under global warming using data from remote weather stations (AMeDAS). J Agric Meteorol 60:445-450

Matsui T, Yagihashi T, Nakaya T, Tanaka N, Taoda H (2004) Climatic controls on distribution of Fagus crenata forests in Japan. J Veg Sci 15:57-66

Metz C (1978) Basic principles of ROC analysis. Semin Nucl Med 8:283-298

Morin X, Thuiller W (2009) Comparing niche- and process-based models to reduce prediction uncertainty in species range shifts under climate change. Ecology 90:1301-1313

Nakashizuka T (1987) Regeneration dynamics of beech forests in Japan. Vegetatio 69:169-175

Ohsawa M (1993) Latitudinal pattern of mountain vegetation zonation in southern and eastern Asia. J Veg Sci 4:13-18

Parmesan C, Yohe G (2003) A globally coherent fingerprint of climate change impacts across natural systems. Nature 421:3742

Pearson RG, Dawson TP (2003) Predicting the impacts of climate change on the distribution of species: are bioclimate envelope models useful? Global Ecol Biogeogr 12:361-371

Pearson RG, Dawson TP, Liu C (2004) Modelling species distributions in Britain: a hierarchical integration of climate and land-cover data. Ecography 27:285-298

Saruki S, Inoue S, Shiiba Y, Nagasawa H, Ohosaki S, Kubota K (2004) Distribution and growth situation of Suzutake (Sasamorpha borealis) damaged by grazing of Sika deer (Cervus nippon nippon) in Miyazaki Forest of Kyushu University: case study in 2003. Bull Kyushu Univ For 85:47-54 (In Japanese with English summary) 
Suzuki S (1961) Ecology of the Bambusaceous genera Sasa and Sasamorpha in the Kanto and Tohoku districts of Japan, with special reference to their geographical distribution. Ecol Rev 15:131-147

Suzuki S (1978) Index to Japanese Bambusaceae. Gakken, Tokyo, p 384 (In Japanese)

Swets J (1988) Measuring the accuracy of diagnostic systems. Science 240:1285-1293

Tanaka N (2007) PRDB (Phytosociological Relevé Data Base). Available from: http://www.ffpri.affrc.go.jp/labs/prdb/index.html. Accessed June 2008

Thuiller W, Lavorel S, Araújo M, Sykes M, Prentice I (2005) Climate change threats to plant diversity in Europe. Proc Natl Acad Sci USA 102:8245-8250

Tsuyama I, Matsui T, Horikawa M, Kominami Y, Tanaka N (2008a) Habitat prediction and impact assessment of climate change on dwarf bamboo of the section Sasa in Japan. Theory Appl GIS 16:99-113 (In Japanese with English summary)

Tsuyama I, Matsui T, Ogawa M, Kominami Y, Tanaka N (2008b) Habitat prediction and impact assessment of climate change on Sasa kurilensis in eastern Honshu, Japan. Theory Appl GIS 16:11-25 (In Japanese with English summary)

Woodward F (1996) Climate and plant distribution. Cambridge University Press, Cambridge, $188 \mathrm{p}$

Yokozawa M, Goto S, Hayashi Y, Seino H (2003) Mesh climate change data for evaluating climate change impacts in Japan under gradually increasing atmospheric $\mathrm{CO}_{2}$ concentration. J Agric Meteorol 59:117-130

Yuruki T, Aragami K, Inoue S (1977) Ecological studies of Suzutake (Sasa borealis). Bull Kyushu Univ For 50:83-122 (In Japanese with English summary) 